\title{
Experts question precautionary approach
}

Colin Macilwain, Cambridge, Massachusetts

Eight months after the United Nations Biosafety Protocol became the first fully fledged international treaty to incorporate the 'precautionary principle', scientists and lawyers remain deeply divided on the principle's definition and merits.

Last week, at Harvard University's Center for International Development, experts gathered to discuss the impact of the protocol's precautionary approach on the growth of agricultural biotechnology. According to Calestous Juma of the Harvard centre, who convened the meeting, a lack of clarity is causing confusion in developing countries. "It is evident that there is no real agreement on what the precautionary principle means and how it should be applied," he says.

The principle states that potential environmental risks should be dealt with even in the absence of scientific certainty. It has long been advocated by environmentalists, who see it as a more effective way of managing hazards than traditional scientific risk assessments, which call for numbers and hard proof as prerequisites for action.

Some experts say that the principle is too vague to be of much value, either legally or scientifically. "It thrives because it is so ambiguous," says Gary Marchant, a law professor at Arizona State University. "What you end up with is arbitrariness." The sceptics say that the principle's impact on the spread of agricultural biotechnology around the world supports their view.

For Luiz Anthonio Barreto de Castro, head of genetic resources and biotechnology at EMBRAPA, the main agricultural research agency in Brazil, the application of the principle is of pressing concern. Transgenic crops have been banned in his country since 1998, he says, because of a judge's interpretation of a version of the principle included in the Rio Declaration, which emerged from the Earth Summit held in Brazil in 1992.

Yet in India, according to Aarti Gupta of Yale University, the principle has contributed to a well-balanced process in which extensive field trials are preceding the introduction of commercial transgenic crops. Indian regulators support the principle, she says, viewing sound science and a precautionary approach as synonymous.

John Mugabe of the African Centre for Technology Studies in Nairobi says that his continent has split into a hierarchy of approaches. Countries such as South Africa and Kenya are building regulatory regimes based on the principle. But poorer nations cannot do so, he says, and may instead accept transgenic crops simply on the basis that the United States considers them safe.

Critics of biotechnology claim that industrial lobbyists are trying to undermine the

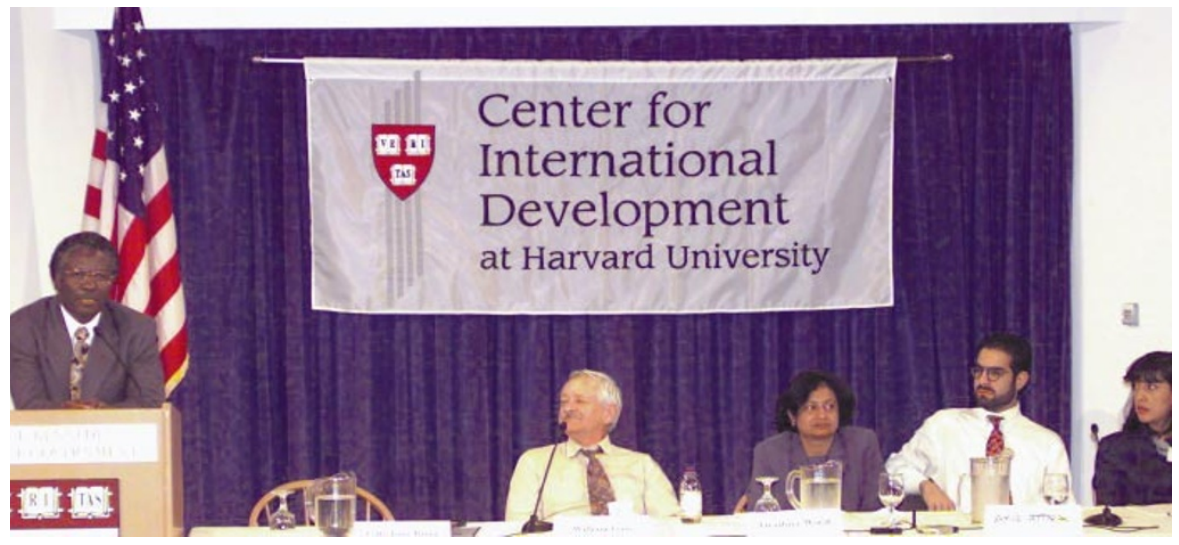

Calestous Juma (left) argues that lack of clarity over the precautionary principle is causing confusion.

Biosafety Protocol. "The precautionary principle is now becoming enshrined in international law, and that is upsetting some powerful interests," says Philip Bereano of the University of Washington in Seattle. Some critics are even unhappy with Juma and Jeffrey Sachs, director of the Center for Internation- al Development, for holding a seminar likely to highlight the principle's shortcomings.

Asked if he intended to praise the principle, or to bury it, Juma laughed and said: "We're a research institute. We're not interested in taking positions on the subject." inttp://www.iisd.ca/sd/biotech/

\section{French lab seeks recipe for success}

\section{Declan Butler, Paris}

Conventional culinary wisdom has it that a soufflé rises because of the dilation of air. In fact, it rises because water vapour is generated inside it - implying that the mould should be heated from the bottom, so that the rising vapour can push up through all the levels. A good crust helps too, as it prevents the vapour escaping.

Now Hervé This - the chemist who, with the late physicist Nicholas Kurti, explored soufflé thermodynamics a decade ago at the Clarendon Laboratory in Oxford - is to set up a laboratory of 'molecular gastronomy' at the Collège de France in Paris. The new facility will be in the Laboratory of Molecular Interaction run by Jean-Marie Lehn, the 1987 Nobel prizewinner in chemistry, who also has an interest in the field.

This's own long-standing interest has been in making cooking as much a science as an art. His PhD thesis was called 'Molecular and physical gastronomy', and the passion remained even after he left research in $\mathbf{1 9 8 0}$ to join Pour la Science, the French edition of Scientific American, of which he later became editor. His return to research has been facilitated by a full-time position offered by INRA, the French national agricultural research organization.

The term 'molecular gastronomy' was coined in 1992 by This and Kurti. Now an international group of scientists who share an interest in the science of cookery plans to establish it as a scientific field. The researchers already hold an annual international meeting on the subject in Erice, Sicily (see Nature 400, 17-18; 1999).

The group defines the field of molecular gastronomy as a distinct subdiscipline of food science. Its main goal is to test scientifically the cooking practices enshrined in the culinary wisdom that has resulted from centuries of empirical work by chefs.

There is no shortage of research questions. Hervé This and his colleagues intend to analyse the factors involved in the many kitchen activities leading to a successful dish, and invent new methods for preparing food. The results will be made available to chefs and to the public.

This himself has published several books, including the French best seller Les Secrets de la Casserole, and his frequent public lectures and television appearances have a large following.

He points out, for example, that microwave ovens often yield disappointing results because the temperatures obtained are too low to provoke the famous Maillard reaction between sugars and amino acids that generates many aromas and flavours.

But take some duck thighs, fry at a high temperature until brown, then take a syringe of Cointreau and inject it into the centre of the meat. Put it in a microwave oven for a few minutes and voilà: a perfect canard à l'orange, Maillard reaction included. 